\title{
Readmissions and Emergency Department Visits after Bariatric Surgery at Saudi Arabian Hospital: The Rates, Reasons, and Risk Factors
}

\author{
Anwar Ahmed $^{a, b} \quad$ Doaa AlBuraikan $^{b} \quad$ Bashayr ALMuqbil $^{b} \quad$ Wijdan AlJohi $^{b}$ \\ Wala Alanazic Budor AlRasheed ${ }^{b}$ \\ ${ }^{a}$ King Abdullah International Medical Research Center (KAIMRC), Riyadh, Saudi Arabia; \\ ${ }^{b}$ King Saud bin Abdulaziz University for Health Sciences, Riyadh, Saudi Arabia; ${ }^{\text {Al-Maarefa }}$ \\ College for Science and Technology, Riyadh, Saudi Arabia
}

\section{Keywords}

Bariatric surgery · Obesity · Gastric sleeve surgery · Readmission · ED visits

\begin{abstract}
Background: Saudi Arabian hospital readmissions and emergency department (ED) visits following bariatric surgery and discharge have never been investigated. This study aimed to evaluate the rates and reasons of hospital readmissions and ED visits related to surgical weight loss interventions at the King Abdulaziz Medical City - Riyadh. Methods: We conducted a retrospective cohort study on 301 patients who underwent bariatric surgery between January 2011 and July 2016. We reviewed patient medical records progressively to assess hospital readmission, ED visits, and complications. Results: Of the 301 patients analyzed, $67.1 \%$ were female and $93 \%$ had class II obesity. The readmission rate, ED visit rate after discharge and the rate of either of the two was $8 \%, 14 \%$, and $18.3 \%$, respectively. The most common causes of readmission were abdominal pain (37.5\%), nausea/vomiting (29.2\%), and site leak (25\%), while the most common causes of ED visits were abdominal pain (59.5\%) and nausea/vomiting (16.9\%). Readmission rates tended to be higher in older patients (age of patients readmitted $42 \pm 12.1$ years vs. age of patients not readmitted $34.3 \pm 11.8$ years; $p=0.002)$. The rate of readmission tends to increase in patients with overweight or class I obesity (odds ratio (OR) $=20.15)$, diabetes $(O R=14.82)$, and obstructive sleep apnea $(O R=14.29)$. Dyslipidemia was positively associated with ED visits ( $p=0.027, O R=2.87$ ). The rate of readmission or ED visits increased with age, while there were decreases in readmission and ED visits for those who had received gastric sleeve surgery. Conclusions: The study reported high rates of readmission and ED visits, thus the effectiveness of different types of weight loss surgeries should be further evaluated, particularly in individuals with complicated medical issues such as diabetes, dyslipidemia, and obstructive sleep apnea.




\section{Introduction}

Obesity is becoming a major public health concern in most countries, especially in Saudi Arabia [1]. According to several epidemiological studies, the rate of obesity was reported between $13 \%$ and $70 \%$ in Saudi societies [1-7], and the rate of obesity continues to increase among Saudi adults [8]. Obesity has been associated with multiple preventable comorbidities and health outcomes, and it increases the risk of mortality [9], diabetes [10], cancer [11], heart disease [12], liver [13], and Helicobacter pylori infection [14]. Bariatric or weight loss surgery is considered one of the possible solutions to reduce weight, especially when no effective treatment is found or when a person fails to self-manage weight. A large epidemiological study noted that weight loss from weight loss surgery is associated with a reduction in comorbidities [15]. In Saudi Arabia, the number of weight loss surgery cases has increased over the years and is likely to continue [16]. This could be due to the limited outdoor activities for females and the cultural restrictions from being physically and socially active [17].

All surgical weight loss interventions can be accompanied by complications and side effects following surgery [18-20]. Monitoring, reporting, and managing unwanted outcomes will help in reducing the burden on healthcare resources and may also help hospital [21] and emergency department (ED) [22] administrators to better manage surgery-related side effects and complications. The post-surgical complications may vary depending on the type of weight loss surgery [23], surgical skills [24], presence of chronic health problems [25], and whether patients are qualified eligible for the specific surgery [26, 27]. Several adverse events and complications after bariatric surgery were observed in the readmissions or ED visits. The most frequent reasons for hospital readmission after bariatric surgery are abdominal pain, nausea, vomiting, wound infections, and dehydration [28-30], while the most frequent reasons for ED visits are abdominal pain, nausea, emesis, dizziness, gastritis, dehydration, pneumonia, renal failure, respiratory failure, infected wound, bowel obstruction, leak, and bleeding [31, 32].

The rates of hospital readmission have been reported in numerous studies. Rosenthal et al. [33] reported a readmission rate of $10.2 \%$ in a study on 985 patients. García-Ruiz-deGordejuela et al. [31] reported that $16.6 \%$ of the patients were readmitted to the ED at least once. Telem et al. [34] reported that $17.5 \%$ of patients who underwent primary bariatric surgery had unplanned ED appearances. Doumouras et al. [35] reported a readmission rate of $6.1 \%$ over a period of 3 years. Saunders et al. [36] reported 1-year readmission rate of $18.8 \%$.

Recognizing potential predictors for hospital admissions and ED visits will allow the healthcare system to establish guidelines regarding prerequisites for bariatric surgery and also develop new approaches to reduce the risk of health problems related to obesity. According to international studies, several predictors for hospital readmission or ED visits after bariatric surgery were identified. The most important predictors for readmission were found to be age, sex, BMI, diabetes, steroid use, hypertension, type of procedure, and operative time $[28,35,37]$. In addition, the surgical procedure type has been associated with postoperative ED visits [31].

In the King Abdulaziz Medical City - Riyadh, the most commonly performed types of bariatric surgical procedures are the sleeve gastrectomy and the Roux-en-Y gastric bypass. The hospital performs nearly 100 cases annually, and the demand for these surgeries continues to increase. This may lead to an increase in hospital readmissions and ED visits to manage bariatric surgery-related side effects. However, the rates and reasons for hospital admissions and ED visits due to bariatric surgery are unknown and have never been investigated in the Saudi population. This study aimed to evaluate the rates and reasons for postop- 
Ahmed et al.: Readmissions and Emergency Department Visits after Bariatric Surgery at Saudi Arabian Hospital: The Rates, Reasons, and Risk Factors

erative hospital readmissions and ED visits following bariatric surgery and characterize potential risk factors for those readmissions and ED visits. Such a study will offer greater insight for future studies and improve perioperative patient care. The secondary aim was to identify the most common surgical approach used in our hospital as well as its related readmissions and ED visits.

\section{Material and Methods}

We conducted a retrospective cohort study on 301 patients who underwent weight loss surgeries at the King Abdulaziz Medical City - Riyadh between January 2011 and July 2016. The study was approved by the Institutional Review Board (IRB) at King Abdullah International Medical Research Center (KAIMRC), Ministry of National Guard - Health Affairs (NGHA), research protocol \#RSS/0001. Participants in the study were patients with ages ranging between 12 and 64 years. We utilized patient discharge records and patient files to review medical records progressively from the date of the procedure until July 2016. We recorded data about patients' demographics: age, gender, weight, height, and BMI. Patients were classified into two groups according to BMI: i) overweight or class I obesity (BMI between 25 and $34.9 \mathrm{~kg} / \mathrm{m}^{2}$ ) and ii) class II (BMI $35-39.9 \mathrm{~kg} / \mathrm{m}^{2}$ ) or class III obesity (BMI $\geq 40 \mathrm{~kg} / \mathrm{m}^{2}$ ). Patient clinical and medical histories were extracted from the medical records: diabetes mellitus, hypertension, prior bariatric surgery, asthma, dyslipidemia, kidney failure, heart disease, obstructive sleep apnea, thyroid, and gastroesophageal reflux disease. The types of operative procedures were also collected. There are two common procedures used in Saudi Arabia: laparoscopic sleeve gastrectomy and laparoscopic Roux-en-Y gastric bypass. We also included other weight loss procedures such as adjustable gastric band and removal of adjustable gastric band. We collected data for a number of procedures completed during the same operation and classified them into one procedure versus two or more procedures. Hospital length of stay was reported in days by subtracting the date of discharge from the date of procedure admission. Procedure duration time was reported in hours.

\section{Outcomes}

The outcomes of the study were hospital readmission and ED visit. We reviewed patient files to identify whether each patient had bariatric surgery-related hospital readmission or ED visit. We collected data on patients who were readmitted or had ED visits to identify the causes of each readmission. We also measured the number of days to hospital readmission or ED visit after 180 days of bariatric surgery.

\section{Statistical Analyses}

The data analysis was conducted using SPSS Statistics 23 (SPSS, Chicago, IL, USA). The rate of hospital readmission, ED visit, and either of the two were reported in percent (\%) with 95\% confidence intervals (CI).

Patients' Characteristics

Descriptive statistics such as means and standard deviation (mean \pm SD) were used to describe the quantitative variables. Frequencies and percentages $\mathrm{n}(\%)$ were used to describe categorical variables.

Bivariate Analyses

Demographic and clinical characteristics were presented by counts and percentages and checked by chi-square test to determine their connections with hospital readmission and/or ED visits after bariatric surgery. An independent sample t-test or Mann-Whitney U test was used to compare age, duration of operation/hours, and hospital length of stay/days between groups.

Multivariate Analyses

A stepwise binary logistic regression model was used to identify predictors of hospital readmission and/or ED visits after bariatric surgery. We also used the Cox proportional hazards model to identify the important factors associated with hospital readmission or ED visit after 180 days of bariatric surgery. In all analyses, $\mathrm{p}<0.05$ was considered significant. 
Ahmed et al.: Readmissions and Emergency Department Visits after Bariatric Surgery at Saudi Arabian Hospital: The Rates, Reasons, and Risk Factors

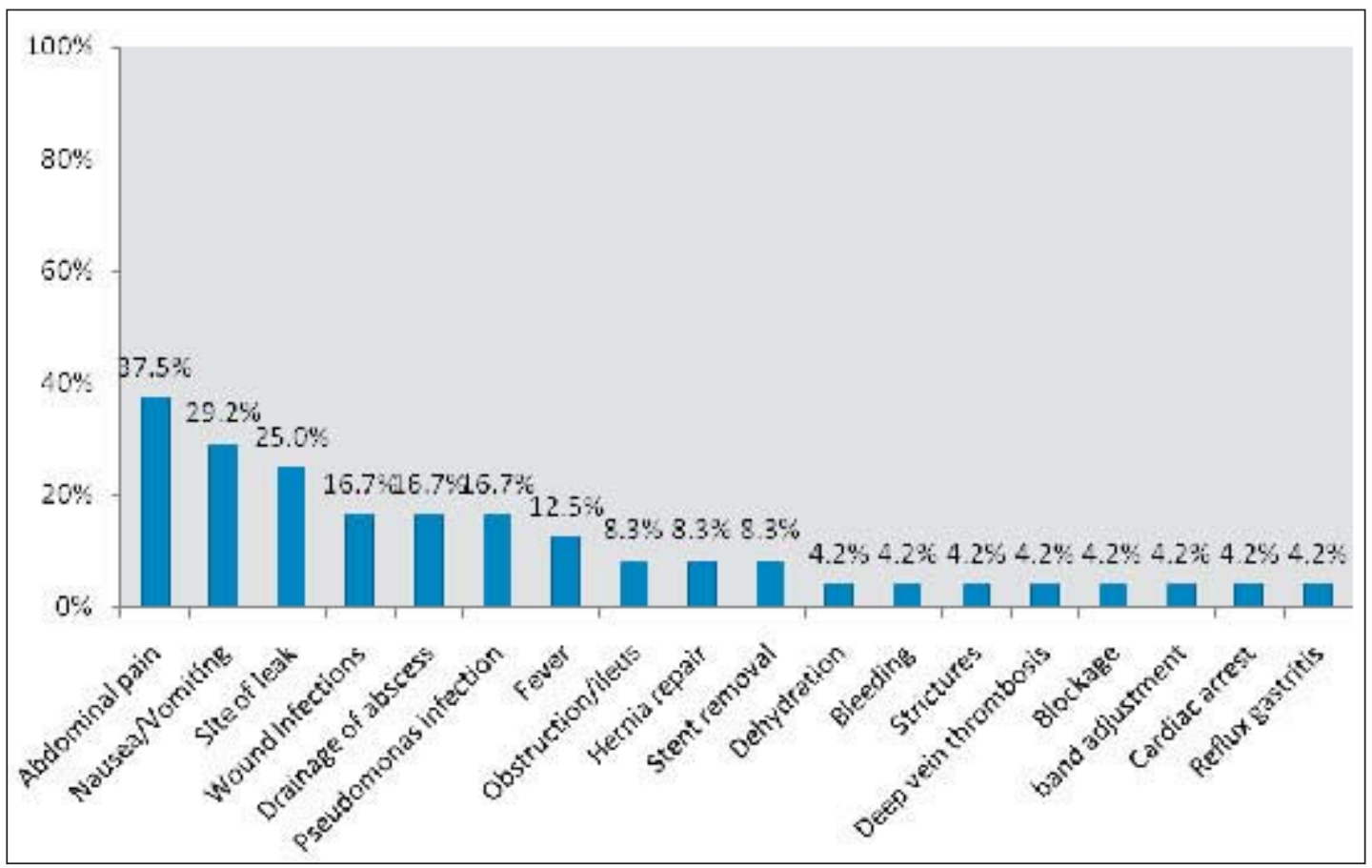

Fig. 1. Reasons for hospital readmission after weight loss surgery $(n=24)$.

\section{Results}

Of 301 patients analyzed, $67.1 \%$ were female and $93 \%$ had class II/III obesity. Of the sample, $15 \%$ had previous bariatric surgery, $23.6 \%$ had hypertension, $18.9 \%$ had diabetes mellitus, and $13.3 \%$ had asthma. Table 1 illustrates the other sample characteristics. The hospital readmission rate was $24 / 300$ (8\%, 95\% CI 5.2-11.6\%). The ED visits rate was $42 / 301$ (14\%, 95\% CI 10.2-18.4\%). The rate of both (either event) was 55/301 (18.3\%, 95\% CI 14.1-23.1\%). In the 24 readmitted patients, the most common bariatric surgery-related causes of hospital readmission were abdominal pain (37.5\%), nausea/vomiting (29.2\%), site leak (25\%), wound infections (16.7\%), drainage of abscess (16.7\%), pseudomonas infections $(16.7 \%)$, and fever (12.5\%) (fig. 1), while the most common bariatric surgery-related causes in the 42 patients who had ED visits were abdominal pain (59.5\%), nausea/vomiting (16.7\%), fever (11.9\%), and wound infections (9.5\%) (fig. 2). The majority (75.7\%) of weight loss surgeries performed in our hospital was gastric sleeve gastrectomy, 10.3\% received gastric bypass, and $14 \%$ were treated by other weight loss surgical interventions.

Subgroup analyses are shown in tables 1 and 2 . Readmission rates tended to be higher in older patients (age of patients readmitted $42 \pm 12.1$ years vs. age of patients not readmitted $34.3 \pm 11.8$ years; $p=0.002$ ). The readmission rate was higher in patients with overweight or class I obesity $(28.6 \%)$ than in patients with class II or class III obesity $(6,5 \% ; p=0.003)$. Readmission rates were similar in class II (6.7\%) and class III obesity (6.4\%). Readmission rates tended to be higher in patients with hypertension (14.1\% with vs. $6.1 \%$ without hypertension; $p=0.030$ ) and dyslipidemia ( $16 \%$ with vs. $6.2 \%$ without dyslipidemia; $p=0.039)$. The rates of the hospital readmission and ED visit were higher in patients with overweight or class I obesity $(47.6 \%)$ when compared to patients with in class II or III obesity $(16.1 \%$; $p=$ $0.001)$, in patients with diabetes mellitus $(28.1 \%)$ in comparison to non-diabetic patients 
Ahmed et al.: Readmissions and Emergency Department Visits after Bariatric Surgery at Saudi Arabian Hospital: The Rates, Reasons, and Risk Factors

Table 1. Readmission and ED visits across the sample characteristics

\begin{tabular}{|c|c|c|c|c|c|c|c|c|c|c|}
\hline & \multicolumn{2}{|c|}{$\begin{array}{l}\text { Overall } \\
\mathrm{N}=301\end{array}$} & \multicolumn{3}{|c|}{$\begin{array}{l}\text { Readmission } \\
24(8 \%)\end{array}$} & \multicolumn{2}{|c|}{$\begin{array}{l}\text { ED visits } \\
42(14 \%)\end{array}$} & \multicolumn{3}{|c|}{$\begin{array}{l}\text { ED visits or readmissions } \\
55(18.3 \%)\end{array}$} \\
\hline & $\mathrm{n}$ & $\%$ & $\mathrm{n}$ & $\%$ & $\mathrm{p}$ value & $\mathrm{n}$ & $\% \quad \mathrm{p}$ value & $\mathrm{n}$ & $\%$ & $\mathrm{p}$ value \\
\hline \multicolumn{11}{|l|}{ Gender } \\
\hline Male & 99 & 32.9 & 9 & 9.1 & 0.616 & 12 & 12.20 .542 & 15 & 15.2 & 0.327 \\
\hline Female & 202 & 67.1 & 15 & 7.4 & & 30 & 14.9 & 40 & 19.8 & \\
\hline \multicolumn{11}{|l|}{ BMI } \\
\hline Overweight/class I obesity & 21 & 7.0 & 6 & 28.6 & $0.003^{*}$ & 4 & 19.00 .513 & 10 & 47.6 & $0.001^{*}$ \\
\hline Class II/III obesity & 279 & 93.0 & 18 & 6.5 & & 38 & 13.7 & 45 & 16.1 & \\
\hline \multicolumn{11}{|l|}{ Procedure } \\
\hline Gastric sleeve & 228 & 75.7 & 15 & 6.6 & 0.081 & 28 & 12.30 .264 & 34 & 14.9 & $0.014^{*}$ \\
\hline Gastric bypass & 31 & 10.3 & 2 & 6.5 & & 7 & 22.6 & 7 & 22.6 & \\
\hline Others & 42 & 14.0 & 7 & 16.7 & & 7 & 16.7 & 14 & 33.3 & \\
\hline \multicolumn{11}{|l|}{ Number of procedures } \\
\hline 1 & 92 & 38.0 & 5 & 5.4 & 0.160 & 15 & 16.30 .441 & 17 & 18.5 & 0.869 \\
\hline 2 or more & 150 & 62.0 & 16 & 10.7 & & 19 & 12.8 & 29 & 19.3 & \\
\hline \multicolumn{11}{|l|}{ Prior bariatric surgery } \\
\hline No & 256 & 85.0 & 22 & 8.6 & 0.550 & 37 & 14.50 .545 & 49 & 19.1 & 0.353 \\
\hline Yes & 45 & 15.0 & 2 & 4.4 & & 5 & 11.1 & 6 & 13.3 & \\
\hline \multicolumn{11}{|l|}{ Hypertension } \\
\hline No & 230 & 76.4 & 14 & 6.1 & $0.030^{*}$ & 33 & 14.40 .713 & 40 & 17.4 & 0.476 \\
\hline Yes & 71 & 23.6 & 10 & 14.1 & & 9 & 12.7 & 15 & 21.1 & \\
\hline \multicolumn{11}{|l|}{ Diabetes mellitus } \\
\hline No & 244 & 81.1 & 14 & 5.7 & $0.006^{*}$ & 32 & 13.20 .392 & 39 & 16.0 & $0.034^{*}$ \\
\hline Yes & 57 & 18.9 & 10 & 17.5 & & 10 & 17.5 & 16 & 28.1 & \\
\hline \multicolumn{11}{|l|}{ Asthma } \\
\hline No & 261 & 86.7 & 22 & 8.4 & 0.753 & 36 & 13.80 .845 & 47 & 18.0 & 0.761 \\
\hline Yes & 40 & 13.3 & 2 & 5.0 & & 6 & 15.0 & 8 & 20.0 & \\
\hline \multicolumn{11}{|l|}{ Dyslipidemia } \\
\hline No & 251 & 83.4 & 16 & 6.4 & $0.039 *$ & 31 & 12.40 .074 & 39 & 15.5 & $0.006^{*}$ \\
\hline Yes & 50 & 16.6 & 8 & 16.0 & & 11 & 22.0 & 16 & 32.0 & \\
\hline \multicolumn{11}{|l|}{ Kidney failure } \\
\hline No & 296 & 98.3 & 22 & 7.4 & 0.053 & 40 & 13.60 .145 & 53 & 17.9 & 0.227 \\
\hline Yes & 5 & 1.7 & 2 & 40.0 & & 2 & 40.0 & 2 & 40.0 & \\
\hline \multicolumn{11}{|l|}{ Heart disease } \\
\hline No & 291 & 96.7 & 23 & 7.9 & 0.570 & 40 & 13.80 .636 & 53 & 18.2 & 1.000 \\
\hline Yes & 10 & 3.3 & 1 & 10.0 & & 2 & 20.0 & 2 & 20.0 & \\
\hline \multicolumn{11}{|l|}{ Obstructive sleep apnea } \\
\hline No & 273 & 90.7 & 19 & 7.0 & 0.058 & 38 & 14.01 .000 & 49 & 17.9 & 0.650 \\
\hline Yes & 28 & 9.3 & 5 & 17.9 & & 4 & 14.3 & 6 & 21.4 & \\
\hline \multicolumn{11}{|l|}{ Thyroid } \\
\hline No & 275 & 91.4 & 23 & 8.4 & 0.706 & 38 & 13.90 .771 & 50 & 18.2 & 0.797 \\
\hline Yes & 26 & 8.6 & 1 & 3.8 & & 4 & 15.4 & 5 & 19.2 & \\
\hline \multicolumn{11}{|l|}{ GERD } \\
\hline No & 280 & 93.0 & 23 & 8.2 & 1.000 & 37 & 13.30 .191 & 50 & 17.9 & 0.556 \\
\hline Yes & 21 & 7.0 & 1 & 4.8 & & 5 & 23.8 & 5 & 23.8 & \\
\hline
\end{tabular}

${ }^{*}$ Chi-square test or Fisher's exact test is significant at $\alpha=0.05$.

GERD = Gastroesophageal reflux disease. 
Ahmed et al.: Readmissions and Emergency Department Visits after Bariatric Surgery at Saudi Arabian Hospital: The Rates, Reasons, and Risk Factors

Table 2. Readmission and ED visits across the sample characteristics

\begin{tabular}{|c|c|c|c|c|c|c|c|c|c|c|}
\hline & \multirow[t]{2}{*}{$\begin{array}{l}\text { Overall } \\
\mathrm{N}=301\end{array}$} & \multicolumn{3}{|c|}{$\begin{array}{l}\text { Readmission } \\
24(8 \%)\end{array}$} & \multicolumn{3}{|l|}{$\begin{array}{l}\text { ED visits } \\
42(14 \%) \\
\end{array}$} & \multicolumn{3}{|c|}{$\begin{array}{l}\text { ED visits or readmissions } \\
55(18.3 \%)\end{array}$} \\
\hline & & no & yes & $\mathrm{p}$ value & no & yes & $\mathrm{p}$ value & no & yes & $\mathrm{p}$ value \\
\hline Mean age (SD) & $\begin{array}{l}34.9 \\
(12.0)\end{array}$ & $\begin{array}{l}34.3 \\
(11.8)\end{array}$ & $\begin{array}{l}42.0 \\
(12.1)\end{array}$ & 0.002 & $\begin{array}{l}34.4 \\
(12.1)\end{array}$ & $\begin{array}{l}37.9 \\
(10.7)\end{array}$ & 0.087 & $\begin{array}{l}34 \\
(11.9)\end{array}$ & $\begin{array}{l}39.0 \\
(11.3)\end{array}$ & 0.005 \\
\hline $\begin{array}{l}\text { Median duration } \\
\text { of operation, } \\
\mathrm{h}(\mathrm{q} 1-\mathrm{q} 3)\end{array}$ & $\begin{array}{l}2.3 \\
(1.9-2.8)\end{array}$ & $\begin{array}{l}2.3 \\
(1.8-2.8)\end{array}$ & $\begin{array}{l}2.3 \\
(2.1-2.60)\end{array}$ & 0.656 & $\begin{array}{l}2.3 \\
(1.9-2.8)\end{array}$ & $\begin{array}{l}2.2 \\
(1.8-2.7)\end{array}$ & 0.405 & $\begin{array}{l}2.3 \\
(1.9-2.87)\end{array}$ & $\begin{array}{l}2.2 \\
(1.8-2.6)\end{array}$ & 0.565 \\
\hline $\begin{array}{c}\text { Median hospital } \\
\text { length of stay, } \\
\text { days (q1-q3) }\end{array}$ & $\begin{array}{l}4 \\
(3-5)\end{array}$ & $\begin{array}{l}4 \\
(3-5)\end{array}$ & $\begin{array}{l}5 \\
(1-7)\end{array}$ & 0.42 & $\begin{array}{l}4 \\
(3-5)\end{array}$ & $\begin{array}{l}4.5 \\
(3.5-6)\end{array}$ & 0.158 & $\begin{array}{l}4 \\
(3-5)\end{array}$ & $\begin{array}{l}4 \\
(2.5-6)\end{array}$ & 0.638 \\
\hline
\end{tabular}

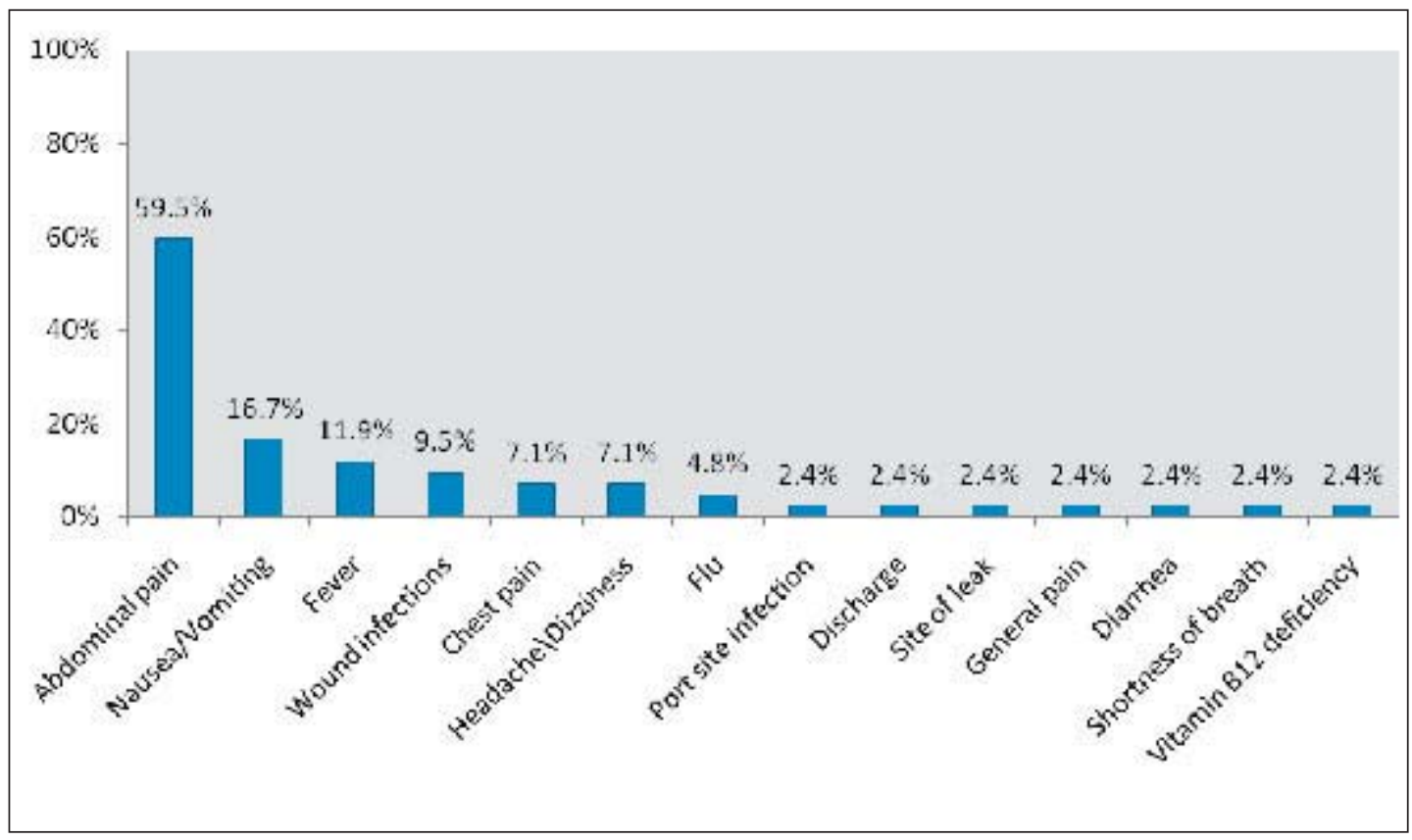

Fig. 2. Reasons for ED visits after weight loss surgery $(n=42)$.

(16\%; $\mathrm{p}=0.034)$, and in patients with dyslipidemia (32\%) when compared to patients without dyslipidemia $(15.5 \%$; $\mathrm{p}=0.006)$. The type of surgical technique was also associated with hospital readmission or ED visit. Gastric sleeve gastrectomy had a lower rate of hospital readmission or ED visit (14.9\%) than gastric bypass $(22.6 \%)$ and other surgical weight loss interventions $(33.3 \%)(\mathrm{p}=0.014)$.

Table 3 identifies the most important risk factors for hospital readmission and/or postsurgical ED visits. The most important predictors of readmission were overweight or class I obesity ( $\mathrm{p}=0.001$, adjusted odds ratio (aOR) 20.15, 95\% CI 4.206-96.497) diabetes ( $\mathrm{p}=$ 0.001, aOR 14.82, 95\% CI 3.537-62.098), and obstructive sleep apnea ( $\mathrm{p}=0.004$, aOR 14.29, 
Ahmed et al.: Readmissions and Emergency Department Visits after Bariatric Surgery at Saudi Arabian Hospital: The Rates, Reasons, and Risk Factors

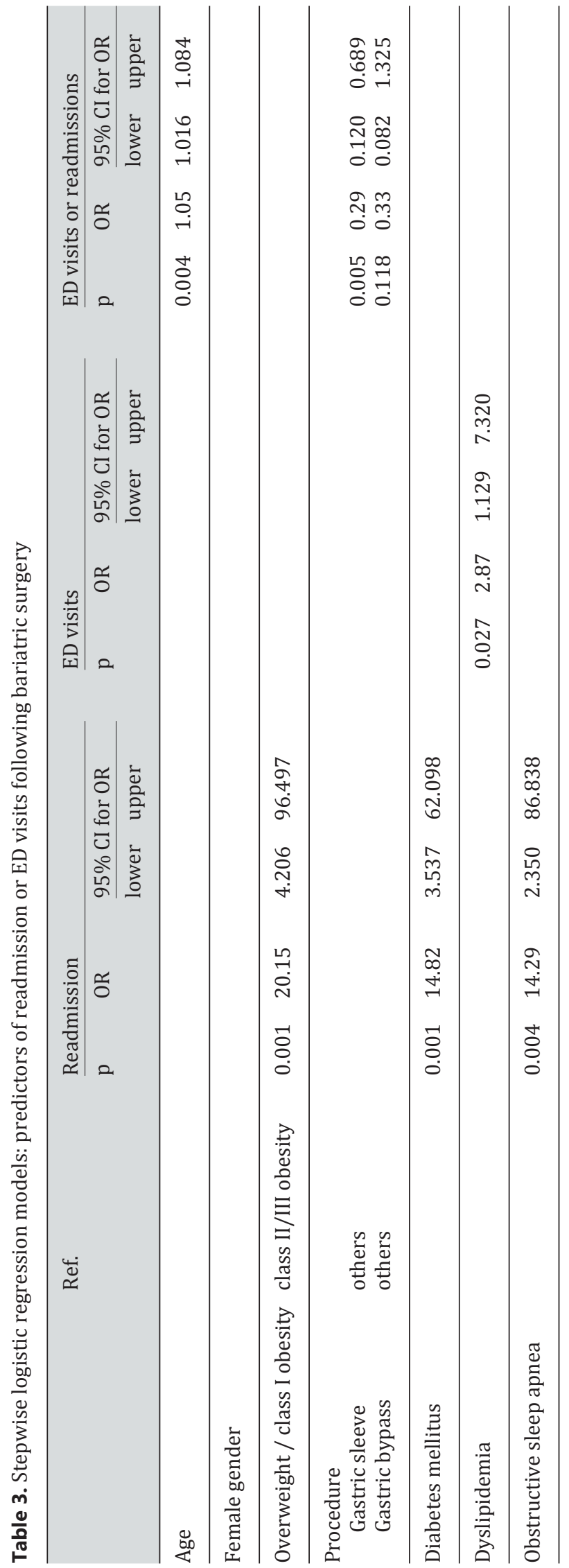


Ahmed et al.: Readmissions and Emergency Department Visits after Bariatric Surgery at Saudi Arabian Hospital: The Rates, Reasons, and Risk Factors

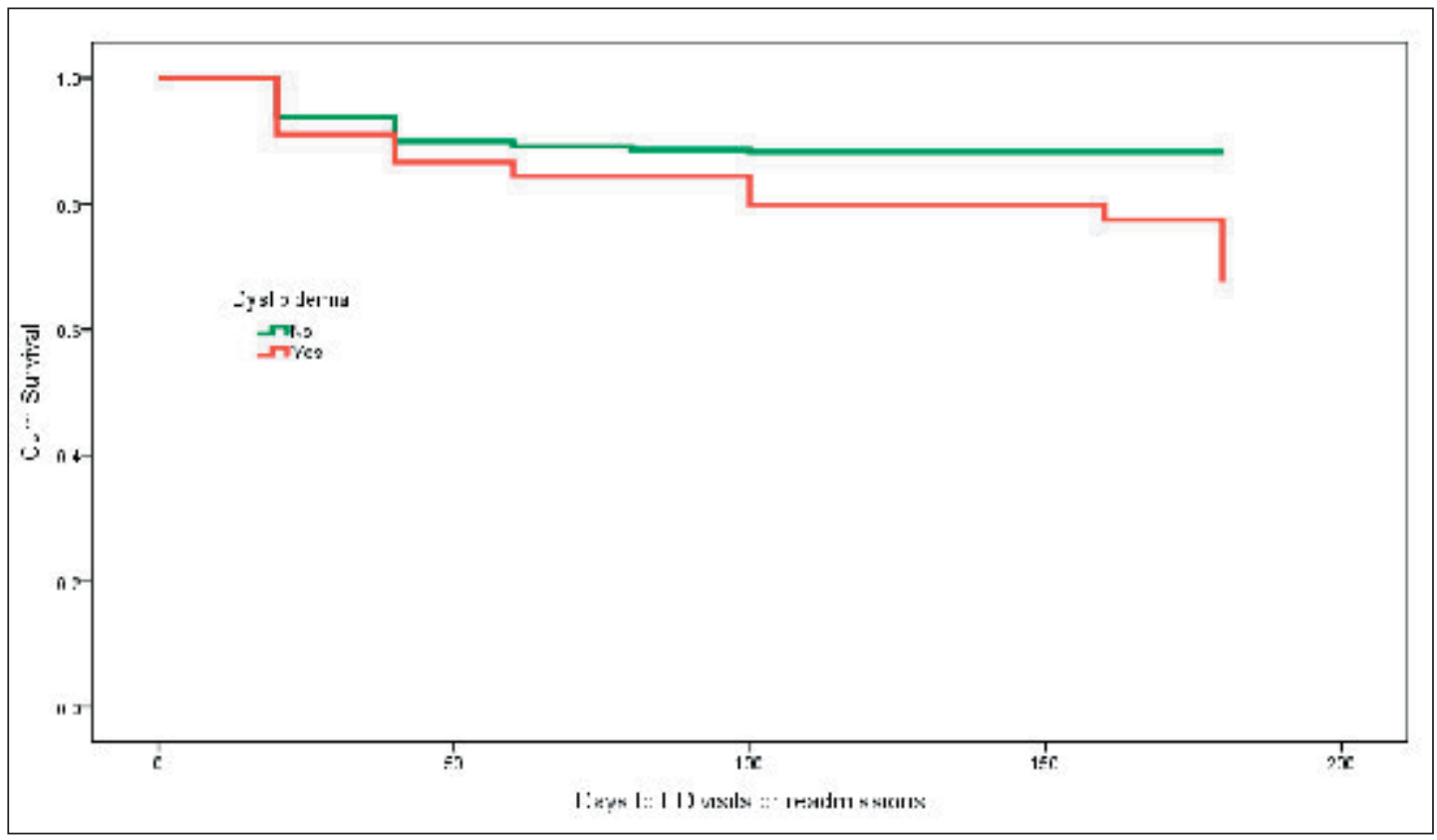

Fig. 3. The effect of dyslipidemia on days to ED visits or hospital readmissions.

95\% CI 2.350-86.838). Dyslipidemia was positively associated with ED visit ( $\mathrm{p}=0.027$, aOR $2.87,95 \%$ CI 1.129-7.320). The rate of readmission or ED visit increased with age ( $p=0.004$, aOR 1.05, 95\% CI 1.016-1.086), while there were decreased return visits in gastric sleeve surgery ( $p=0.005$, aOR $0.29,95 \%$ CI $0.120-0.689$ ). Time to readmission or ED visit was influenced by dyslipidemia (fig. 3). Cox proportional hazards model stepwise analysis indicated that the hazard of readmission or ED visit in patients with dyslipidemia was 3.5 times higher than in patients without dyslipidemia ( $p=0.001$, Hazard ratio $3.5,95 \%$ CI 1.738-6.999).

\section{Discussion}

Obesity has become a public health challenge in many countries around the world, especially in the Gulf region in general and in the Saudi Arabian society in particular. Using diet and exercise may not always work for individuals with extreme obesity to reduce excess weight. Thus, bariatric surgery can be performed as an alternative approach to lose weight in individuals with obesity class II/III who suffer from weight-related health problems. Recently, weight loss surgery has received considerable attention in Saudi Arabia. Despite the importance of weight loss surgery in reducing the risk of weight-related health problems, there have been no studies that document complications following weight loss surgery, such as the reasons for - and numbers of - hospital readmissions or ED visits. There could be significant benefits in recognizing complications after bariatric surgery in the Saudi population as well as by identifying minimal invasive weight loss surgeries and potential patients at high risk of readmission who may not be qualified for such interventions.

In our study, we retrieved data on surgical weight loss interventions at King Abdulaziz Medical City - Riyadh from January 2011 to July 2016. A sample of 301 cases were identified and included in the analysis. The hospital readmission rate was high in our sample (8\%). It 
Ahmed et al.: Readmissions and Emergency Department Visits after Bariatric Surgery at Saudi Arabian Hospital: The Rates, Reasons, and Risk Factors

may be possible that this rate has been impacted by the comorbid conditions of these patients (23.6\% of the sample had hypertension, and $18.9 \%$ had diabetes mellitus). For instance, the readmission rate was $5.7 \%$ in patients with no diabetes compared to $17.5 \%$ in patients with diabetes. A study is needed to assess the relationship between comorbid conditions and the reasons for readmission. Our study finding is similar to those of several international studies that assessed the rate of hospital readmissions and complications following bariatric surgery, with reported rates ranging between 0.6 and $11.75 \%$ [24, 28, 38-44]. Our study reported that $18 \%$ had ED visits following surgery. This finding is similar to a previous study indicating that $18.2 \%$ of the patients had readmission, outpatient hospital visit, or ED visit [22]. As with any general surgery, weight loss surgery may involve adverse effects and risks that may cause hospital readmission or post-surgical ED visits. In our population, we noted abdominal pain, nausea/vomiting, site leak, wound infections, drainage of abscess, and fever as the most common causes of hospital readmission. The most common causes of ED visits were abdominal pain, nausea/vomiting, wound infections, and fever. Several previous international studies in different populations have shown similar reasons for readmission after weight loss surgery [28-31, 45].

Our study has identified several independent predictors of readmission and ED visits revealing that the risk of hospital readmission among patients with diabetes is approximately 15 times higher than in those without diabetes, and is 14 times higher in patients with obstructive sleep apnea than those without. These predictors have also been identified in previous studies where the readmission rate was higher in diabetes and obstructive sleep apnea patients [46-48].

Garg et al. [46] noted that readmission is positively associated with increased BMI. Our findings contradict their report, as there is a negative association between BMI and readmission, with lower BMI increasing the likelihood of readmission and ED visits. We noticed that the readmission rate was higher among overweight or class I obesity patients than in those with class II or III obesity. Possible explanations for the high readmission rate in patients with overweight or class l obesity could be related to the type of surgery used. There is evidence that patients with overweight/class I obesity undergoing procedures such as adjustable gastric banding had more readmissions (46.2\%) than those undergoing sleeve gastrectomy (0\%) or Roux-en-Y gastric bypass (0\%). According to the guidance for commissioning obesity surgery, surgery may only be considered if the BMI is $40 \mathrm{~kg} / \mathrm{m}^{2}$ or higher, or if the BMI ranges between 35 and $40 \mathrm{~kg} / \mathrm{m}^{2}$ and are comorbidities are present. Fulfilling this guidance may reduce postsurgical readmissions and improve patient outcomes. In our population, laparoscopic sleeve gastrectomy has fewer readmissions than other surgical weight loss interventions. The readmission rate in laparoscopic sleeve gastrectomy tends to decrease by $70 \%$ as compared to other surgical approaches. This is consistent with a study by Lalor et al. [49] who reported that laparoscopic sleeve gastrectomy is a relatively safe approach. The readmissions and ED visits may be affected by patient characteristics such as age, inasmuch as the readmission rate was found to increase as age increased. The findings of the current study highlighted the need for postoperative follow-up programs or interventional programs to assess specific risks associated with different types of surgical weight loss interventions, thus reducing readmission and ED utilization.

\section{Conclusions}

The present study reported high rates of readmission and ED visits. Thus the effectiveness of different types of surgical weight loss interventions should be evaluated further, particularly in individuals with comorbidities such as diabetes, dyslipidemia, and obstructive 
sleep apnea. Patients' experiences are important in evaluating these surgical interventions continuously, as they should be followed up and routinely assessed to determine whether they achieve their ultimate goals. In our study increased age of patients, diabetes, obstructive sleep apnea, and overweight/class I obesity were associated with higher readmission and ED visits.

\section{Acknowledgements}

The authors would like to thank King Abdullah International Medical Research Center for approving and partially funding this study.

\section{Funding} Center.

This study was partially supported by grants from the King Abdullah International Medical Research

\section{Authors' Contributions}

AEA conceived and designed the study, carried out the data analysis, and prepared the manuscript. DAA, BIA, WAA, WRA, and BAA helped in preparing the introduction, data collection, and entry. All authors read and approved the final manuscript.

\section{Consent for Publication}

Not applicable, as the manuscript does not contain any identifiable individual's data.

\section{Availability of Data and Materials}

The data are not publicly available because of confidentiality concerns due to the nature of the study. However, all relevant and supporting data are contained within the manuscript.

\section{Ethics Approval and Consent to Participate}

The study received ethical approval from the Institutional Review Board at King Abdullah International Medical Research Center.

\section{Disclosure Statement}

The authors declare that they have no competing interests. 
Ahmed et al.: Readmissions and Emergency Department Visits after Bariatric Surgery at Saudi Arabian Hospital: The Rates, Reasons, and Risk Factors

\section{References}

1 Al-Nuaim AR, Al-Rabeaan K, Al-Mazrou Y, Al-Attas O, Al-Daghari N, Khoja J: High prevalence of overweight and obesity in Saudi Arabia. Int J Obes 1996;6:547-552.

2 Al-Shammari SA, Khoja TA, Al-Maatouq MA, Al-Nuaim LA: High prevalence of clinical obesity among Saudi females: a prospective, cross-sectional study in the Riyadh region. J Trop Med Hyg 1994;97:3:183-188.

3 Hamilton CJ, Jaroudi KA, Sieck UV: High prevalence of obesity in a Saudi infertility population. Ann Saudi Med 1995;4:344-346.

4 El-Hazmi MA, Warsy AS: Prevalence of obesity in the Saudi population. Ann Saudi Med 1997;17:302-306.

5 Hajian-Tilaki KO, Heidari B: Prevalence of obesity, central obesity and the associated factors in urban population aged 20-70 years, in the north of Iran: a population-based study and regression approach. Obes Rev 2007;8:3-10.

6 Al-Nuaim AA, Bamgboye EA, Al-Rubeaan KA, Al-Mazrou Y: Overweight and obesity in Saudi Arabian adult population, role of sociodemographic variables. J Commun Health 1997;3:211-323.

7 Memish ZA, El Bcheraoui C, Tuffaha, M, et al: Obesity and associated factors - Kingdom of Saudi Arabia, 2013. Prev Chronic Dis 2014;11:E174.

8 Al-Nozha MM, Al-Mazrou YY, Al-Maatouq MA, et al: Obesity in Saudi Arabia. Saudi Med J 2005;824-829.

9 Masters RK, Powers DA, Link BG: Obesity and US mortality risk over the adult life course. Am J Epidemiol 2013; 431-442.

10 Horaib GB, Al-Khashan HI, Mishriky AM, et al: Prevalence of obesity among military personnel in Saudi Arabia and associated risk factors. Saudi Med J 2013;401-407.

11 Deslypere JP: Obesity and cancer. Metabolism 1995;44(9 suppl 3):24-27.

12 Hubert HB, Feinleib M, McNamara PM, Castelli WP: Obesity as an independent risk factor for cardiovascular disease: a 26-year follow-up of participants in the Framingham Heart Study. Circulation 1983;968-977.

13 Al Akwaa A, El Zubier A, Al Shehri M: Pattern of liver function tests in morbidly obese Saudi patients undergoing bariatric surgery. Saudi J Gastroenterol 2011;17:252-255.

14 Al-Akwaa AM: Prevalence of Helicobacter pylori infection in a group of morbidly obese Saudi patients undergoing bariatric surgery: a preliminary report. Saudi J Gastroenterol 2010;16:264-267..

15 Colquitt JL, Pickett K, Loveman E, Frampton GK: Surgery for weight loss in adults. Cochrane Database Syst Rev 2014;8:CD003641.

16 Mofti AB, Al-Saleh MS: Bariatric surgery in Saudi Arabia. Ann Saudi Med 1992;5:440-445.

17 Alqout 0, Reynolds F: Experiences of obesity among Saudi Arabian women contemplating bariatric surgery: An interpretative phenomenological analysis. J Health Psychol 2014;5:664-677.

18 Martin JA, Pandolfino JE: Gastrointestinal complications of bariatric surgery. Curr Gastroenterol Rep 2005;4: 321-328.

19 Huang CS, Farraye FA: Complications following bariatric surgery. Techniques Gastrointest Endosc 2006;2: 54-65.

20 Schein M, Assalia A, Rogers P: Schein's Common Sense Emergency Abdominal Surgery. Heidelberg, Springer, 2009.

21 Zingmond DS, McGory ML, Ko CY: Hospitalization before and after gastric bypass surgery. JAMA 2005; 15: 1918-1924.

22 Encinosa WE, Bernard DM, Chen CC, Steiner CA: Healthcare utilization and outcomes after bariatric surgery. Med Care 2006;44:8:706-712.

23 Regan JP, Inabnet WB, Gagner M, Pomp A: Early experience with two-stage laparoscopic Roux-en-Y gastric bypass as an alternative in the super-super obese patient. Obes Surg 2003;13:6:861-864.

24 Birkmeyer JD, Finks JF, O’Reilly A, et al: Surgical skill and complication rates after bariatric surgery. N Engl J Med 2013;369:1434-1442.

25 Buchwald H, Estok R, Fahrbach K, et al: Weight and type 2 diabetes after bariatric surgery: systematic review and meta-analysis. Am J Med 2009;122:248-256.

26 Mechanick JI, Youdim A, Jones DB, et al: Clinical practice guidelines for the perioperative nutritional, metabolic, and nonsurgical support of the bariatric surgery patient - 2013 update: cosponsored by American Association of Clinical Endocrinologists, the Obesity Society, and American Society for Metabolic \& Bariatric Surgery. Obesity (Silver Spring) 2013;21(suppl 1):S1-27.

27 Sauerland S, Angrisani L, Belachew M, et al: Obesity surgery: evidence-based guidelines of the European Association for Endoscopic Surgery (EAES). Surg Endosc 2005;19:200-221.

28 Aman MW, Stem M, Schweitzer MA, Magnuson TH, Lidor AO: Early hospital readmission after bariatric surgery. Surg Endosc 2016;30:2231-2238.

29 Hong B, Stanley E, Reinhardt S, Panther K, Garren MJ, Gould JC: Factors associated with readmission after laparoscopic gastric bypass surgery. Surg Obes Relat Dis 2012;8:6:691-5.

30 Kellogg TA, Swan T, Leslie DA, Buchwald H, Ikramuddin S: Patterns of readmission and reoperation within 90 days after Roux-en-Y gastric bypass. Surg Obes Relat Dis 2009;5:4:416-423.

31 García-Ruiz-de-Gordejuela A, Madrazo-González Z, Casajoana-Badia A, Muñoz-Campaña A, Cuesta-González FJ, Pujol-Gebelli J: Evaluation of bariatric surgery patients at the emergency department of a tertiary referral hospital. Rev Esp Enferm Dig 2015;107:23-28. 
Ahmed et al.: Readmissions and Emergency Department Visits after Bariatric Surgery at Saudi Arabian Hospital: The Rates, Reasons, and Risk Factors

32 Gonzalez-Sánchez JA, Corujo-Vázquez 0, Sahai-Hernández M: Bariatric surgery patients: reasons to visit emergency department after surgery. Bol Asoc Med P R 2006; 99:4:279-283.

33 Rosenthal RJ, Montorfano LM, Abdemur A, et al: Readmission rates of bariatric procedures. J Am Coll Surg 2015;221:4:e47-48.

34 Telem DA, Yang J, Altieri M, Patterson W, et al: Rates and risk factors for unplanned emergency department utilization and hospital readmission following bariatric surgery. Ann Surg 2016;263:5:956-960.

35 Doumouras AG, Saleh F, Hong D: 30-Day readmission after bariatric surgery in a publicly funded regionalized center of excellence system. Surg Endosc 2016;30:5:2066-2072.

36 Saunders J, Ballantyne GH, Belsley S, et al: One-year readmission rates at a high volume bariatric surgery center: laparoscopic adjustable gastric banding, laparoscopic gastric bypass, and vertical banded gastroplasty-Roux-en-Y gastric bypass. Obes Surg 2008;18:10:1233-1240.

37 Abraham CR, Werter CR, Ata A, et al: Predictors of hospital readmission after bariatric surgery. J Am Coll Surg 2015;221:1:220-227.

38 Escinosa WE, Bernard DM, Chen C, et al: Healthcare utilization and outcomes after bariatric surgery. Med Care 2006;44:706-712.

39 Nguyen NT, Paya M, Stevens CM, et al: The relationship between hospital volume and outcome in bariatric surgery at academic medical centers. Ann Surg 2004;240:586-594.

40 McCarty TM, Arnold DT, Lamont JP, et al: Optimizing outcomes in bariatric surgery: outpatient laparoscopic gastric bypass. Ann Surg 2005;242:494-498.

41 Mehrotra C, Serdula M, Naimi TS, et al: Population-based study of trends, costs, and complications of weight loss surgeries from 1990 to 2002 Obes Res 2005;13:2029-2034.

42 Baker MT, Lara MD, Larson CJ, et al: Length of stay and impact on readmission rates after laparoscopic gastric bypass. Surg Obes Relat Dis 2006;2:435-439.

43 Bradley DW, Sharma BK: Centers of excellence in bariatric surgery: design, implementation, and one-year outcomes. Surg Obes Relat Dis 2006;2:513-517.

44 Weller WE, Rosati C, Hannan EL: Relationship between surgeon and hospital volume and readmission after bariatric operation. J Am Coll Surg 2007;204:383-391.

45 Thodiyil PA, Yenumula P, Rogula T, et al: Selective nonoperative management of leaks after gastric bypass: lessons learned from 2675 consecutive patients. Ann Surg 2008;248:5:782-792.

46 Garg T, Rosas U, Rivas H, Azagury D, Morton JM: National prevalence, causes, and risk factors for bariatric surgery readmissions. Am J Surg 2016;212:76-80.

47 Chopra T, Marchaim D, Lynch Y, et al: Epidemiology and outcomes associated with surgical site infection following bariatric surgery. Am J Infect Control 2012;40:9:815-819.

48 Dorman RB, Miller CJ, Leslie DB, et al: Risk for hospital readmission following bariatric surgery. PLoS One 2012;7:3:e32506.

49 Lalor PF, Tucker ON, Szomstein S, Rosenthal RJ: Complications after laparoscopic sleeve gastrectomy. Surg Obes Relat Dis 2008;4:1:33-38. 